\title{
Transitivity in Stylistics: Protest Through Animal Proverbs in Bole Butake's and Palm Wine Will Flow
}

\author{
SEINO Evangeline Agwa Fomukong \\ Higher Teacher Training College (HTTC), The University of Bamenda, P.O. Box 39, Bambili - Bamenda, Cameroon \\ E-mail: seinoeva2014@yahoo.com
}

Doi:10.7575/aiac.alls.v.8n.3p.91

URL: http://dx.doi.org/10.7575/aiac.alls.v.8n.3p.91
Received: 19/04/2017

Accepted: 04/06/2017

\begin{abstract}
Stylistic effects of transitivity in the use of animal proverbs in Bole Butake's And Palm Wine Will Flow, analyses the message the author is passing through the use of animal proverbs. Systemic functional theory views language as a resource people use to accomplish their purposes by expressing meaning in context. Particular aspects of a given context define the meanings likely to be expressed and the language likely to be used to express those meanings. The method of analysis is a descriptive approach that describes the proverbs and the relationship between the animals used in the proverbs, showing opposition in the animal camp. Butake brings man to the level of the animal because he wants reconciliation in the human society. This is the reason for the excess use of the material process which shows action. Transitivity as used in this study correlates linguistic choices and social aspects of language use, and brings out the underlying message of protest in the play.
\end{abstract}

Keywords: Field, transitivity, animal, proverbs, protest, reconciliation

\section{Introduction}

Systemic functional theory views language as a resource people use to accomplish their purposes by expressing meaning in context. Particular aspects of a given context define the meanings likely to be expressed and the language likely to be used to express those meanings. In addition, particular aspects of context comprise of elements such as topics being discussed, the language users and the medium of communication. Each analysed text can be viewed as having three important facets: ideational, interpersonal and textual. These three facets or metafunctions are directly linked to the concepts in the context of situation which determine the different kinds of meaning expressed. These concepts are field, mode and tenor. The ideational metafunction goes with the field, the interpersonal with the mode and the textual with the tenor.

The field is the total event, in which the text is functioning, together with the purposive activity of the speaker or the writer: it thus includes the subject matter as one element in it (Halliday \& Hasan, 1986, pp. 22). The field of text tells you which domain of experience the text is about: family life, religion, medicine, science. Field is an element of the experiential metafunction of a text. In Systemic Functional Grammar therefore, language represents external reality by happenings and states. Cunanan (2011) in his paper shows how the use of some language resources can unravel to the reader the world view of the person or the writer in a literacy work. Drawing on Systemic Functional Grammar, it attempts to make transitivity framework accessible. It aims at raising one's awareness on the confluence of language structures and can show the connection between linguistics and literature. Under the experiential mode the analyst is concerned with the way the language constructs a representation of reality with the various categories the language makes available for talking about real world happenings. A fundamental property of language is that it enables human beings to build a mental picture of reality, to make sense of their experience of what goes on around them and inside them.

Experience is expressed through the ideational metafunction by clauses that contain a constituent structure described functionally through the use of transitivity, which is made up of participants, processes and circumstances. It is through these meanings that language is able to depict who is involved, what happens and the conditions in which these questions are answered. Transitivity specifies the different types of process that are recognised in the language and the structures by which they are expressed (Halliday 1985b, pp. 101). These processes are expressed in language to talk about our experiences of the world, including the worlds in our own minds, to describe events, states and entities involved in them. In doing so, the writer or speaker encodes their meaning not only from words but also from the contexts in which they appear. One of this kind of language use and interpretation is in proverbs.

Using proverb is an important way of communicating thoughts in a simple, usually popular manner. The proverb expresses a truth, gives an advice and carries metaphoric meaning. Many scholars have described proverbs in different ways. Adesina (2015) explains that, proverbs are used to convey messages which is turn, guide and control the sociocultural aspects of those who understand them. They are therefore used to inform, warn, reprimand, counsel and strengthen communal bonds amongst a cultural group. Proverbs provide an ease of communication in everyday 
conversation, and when people want to make their points stronger, better understood, even convince their listeners, they use proverbs. Asika (2012 pp.14) states that proverb has come to mean a lot and occupy a worthwhile position in the matrix of people's culture as a means of interpreting and understanding several phenomena and events around them. And therefore even with the modernity and technological growth in our society today, proverb has continued to play prominent roles in debates, arguments, sacred and secular events of the people both in literary and non-literary events. Asika (2012, pp. 15) gives Donatus Nwoga's definition of a proverb which 'is a terse statement which figuratively gives expression to the point of traditional wisdom relevant to a given situation.' He gives Chinua Achebe's view of proverbs as 'the palm oil with which words are eaten' and Emmanuel Obiechina's as 'the kernel which contains the wisdom of traditional people.' According to Ayodele (2011) a proverb is 'the vehicle of conversation; when the conversation drops a proverb revives it.' And as Ayodele quotes, to the Arab 'a proverb is to speech what salt is to food,' to the Bosman 'proverbs in conversation are torches in darkness,' and to the Bantu 'what flowers are to garden, spice to food, germ to a garment and stars to heaven such are proverbs interwoven in speech.' Achebe, Obiechina, Ayodele, the Arab, the Bosman, the Bantu all express the importance of proverbs to speech. Ashipu \& Amende (2013, pp. 14) give three fundamental factors that enable the hearer to discover the implicit meaning of a proverbial expression. These are the situations in which the utterance is produced, the shared previous knowledge and the linguistic context in which a particular proverbial expression is used. This is the importance Butake has in mind when he makes his choice of proverbs in And Palm Wine Will Flow. This paper therefore aims to illustrate how Butake's elusive and subjective mind style is realised through the experiential meaning. This is expressed in the remarkable use of animal proverbs in his play, And Palm Wine Will flow. This study uses the concept of transitivity in the experiential metafuntion of Halliday's Systemic Functional Grammar to examine and analyse the reason and effect, of the use of animal proverbs on Butake's readers and his society.

\section{Background To The Study}

Bole Butake (late) was from Nkor Noni which is a minority to Oku and Nso, in the Bui Division, North West Region of Cameroon. He was born in July 1948. Butake was a Professor in the Department of Arts and Archaeology in the University of Yaoundé 1 and was the Vice Dean in Charge of Academic Affairs in the Faculty of Arts, Letters and Social Sciences, University of Yaoundé 1. Before his death in October 2016, he was the Dean of the Faculty of Arts, Social and Managerial Sciences at Cameroon Christian University, Bali, North West Region, Cameroon. He was a playwright, essayist, critic and activist. Some of his plays include: The Rape of Michelle, Lake God, And Palm Wine Will Flow, The Survivors, Shoes and Four Men in Arms, Dance of the Vampire, Marriage without Betrothal, and Family Saga.

The play And Palm Wine Will Flow published by Bole Butake in 1990, is set in Ewawa, a fictional village. The play centres on the power struggle amongst the gods, the Fon (oppressor) and the council of elders (oppressed). It brings to light the problems that result from a dictatorial government and focuses on those asking for divine retribution and the reinststement of justice in the land. The play exposes the Fon who is guilty of irresponsible deeds, like the seizure of farmlands from villagers who do not support him and given to those who give him bribe and hail him, the award of titles indiscriminately to underserving citizens and the ban of the council of elders. The Fon's meanness and lack of foresight lead the chief priest to criticise and denounce his actions. Almost the whole village is against the Fon. Shey Ngong, the chief priest, uses the Earth Goddess and Kibaranko (masquerades-spiritual forces) to bring down the Fon. At the end, the Fon prefers to commit suicide rather than die by drinking the urine of the women of Ewawa brought by Kwengong. Symbolically, And Palm Wine Will Flow is about Butake's society, Cameroon and the wider African continent where there is a cry against dictatorial regimes, and against injustice. In this play Butake looks at the possibility of calling on the spiritual world to mediate in the material world. The fall of the repressive structure in the play is Butake's intention to condemn irresponsible leadership in contemporary Cameroon and Africa.

\section{Related Literature}

Butake wrote And Palm Wine Will Flow against the backdrop of rapacious and inhumane oppressive regimes of the marginalised massed of the fictionalised communities of the North West Province (today North West Region) of the Republic of Cameroon, Africa. This play together with others written by Butake, treat among other issues the themes of corruption, tyranny, nepotism and the rampant abuse of power. Ngwang \& Usongo (2016) conclude in 'women empowerment and political change in Butake works' that Butake shows that the commitment to causes which come naturally to women seems to be what is lacking in men, portray women rising up against the Fon to fight in both the spiritual/scared and political. Takem (2002) portrays Butake in And Palm Wine Will Flow as exploring the possibilities of building a society that fulfils the dreams of the people. He does this by dramatising oppression and resistance. He shows Butake's new vision for a new society as being concretised even in the way his characters struggle and succeed in overthrowing dictatorship. Takem concludes that Butake's drama is a tool for consciousness-raising that has an agenda to condemn irresponsible leadership in contemporary Cameroon. The raising of awareness in the Cameroonian society through the use of proverbs is also analysed in Fomukong (2016). She looks at the micro and macro situational contexts of the use of proverbs by Nkengasong, another Cameroonian write. She concludes that given the knowledge of the cultural background, proverbs can effectively pass across the message of the writer or speaker. This relates to the present study in that both Butake and Nkengasong are Anglophone Cameroonians fighting against marginalisation and the inhumane treatment of citizens. But this study unlike Fomukong (2016), uses the trasitivity theory and focuses on animal proverbs. 
Asika (2012:16-17) gives a signification of proverbs is written African literature. He opines that in written African literature, writers justify the actions of characters, and criticise bad ethical and immoral behaviours. Through proverbs they also express the wealth of philosophy in wisdom and perception of life as they effect and control their works in daily life. The proverb also gives a touch of African beauty and it helps them to enhance the plot of writers' stories. In his work Asika explains the use of proverbs to create and resolve conflict, create suspense, heighten the plot, increase the reader's interest and stimulation, and lead to the emotional purgation in the end. He concludes that African writers do not use proverbs by accident but for specific roles and significances which they perform in the African culture.

Numerous works have shown that Achebe uses proverbs to add distinctively local shade to his settings, to depict the speech patterns and conventions of Igbo characters who would not ordinarily speak English to define these characters by the particular types of proverbs they use and also to exercise narrative control by changing thematic statements as his plots develop.

Adesina (2015) works on the pragmatic use of some proverbs on 'Egungun' among Yoruba speakers. He postulates that every culture depends on context for use in communication among the people. Meaning, whatever intrinsic meaning the grammatical categories may have, context plays a crucial role in the interpretation of such meanings. The context is a common ground for background knowledge understood by both the speaker and the listener. This will help to ease the decoding of the implied meanings of proverbs, since both speaker and hearer must be aware of the social behaviour of language use inherent in communication between them. His analysis shows that proverbs around 'Egungun' (masquerade) by Yoruba speakers are employed with the intention to show their logical structure with the assumption and implications for social interaction and cultural affinity (2015, pp. 5). He sums up his study with the accentuated truth about proverbs that every speech community has a set of rules and codes of behaviours that must be followed and obeyed for mutual cohesion and understanding.

Ashipu \& Amende (2013) examine proverbs as circumstantial speech Acts. They look at proverbs from the oral perspective, that is, in speeches. They focus on the orality of proverbs that are used consciously not only to make effective points but also to embellish their speeches in a way admired and appreciated by their audiences. By their nature, proverbs are indispensable sentential utterances that are commonly used in both private conversation and various forms of public speeches. From the views by scholars therefore, proverbs are considered and used effectively both in written, oral literature and folk languages. What runs through the review is that proverbs are understood contextually whether written or oral. This can be seen in the images used which are familiar to both the speaker and the listener. The use of proverbs in Bole Butake's And Palm Wine Will Flow gives the importance of animals in the culture of the people in the North West Region of Cameroon and the different roles these animals play in the society.

In George Orwell's Animal Farm, animals are used in a didactic way in literature. The animals do not reflect animals in our world but rather function to illustrate some aspects of humanity that might be politically or socially imprudent for the author to address directly. There are other works in literature in which animals are still animals but are presented in a way that allows the reader to identify with the animals' experiences, especially in children's books. Deepak (2011) gives an overview of Ted Hughes' poems especially 'The Hawk in the Rain' (1957), in which animals are presented not as play things but as lords of life and death. They are presented as superior to men who lack self-consciousness. They are found free from inhibitions and fears, and full of courage and concentrations. Deepak finalises that in Hughes poems, animals are far from limits and social values, thus they are capable of living their own self true nature and that specialty makes them powerful and wise. Man on the other hand, is far from living his own true nature due to the limitations and social values which block the use of instincts. Thus man is not free, man is confused, ignorant and lost. Butake does not use animals like Hughes but in a way that the beastly nature of the animal is shown to make man retreat from greed, tyranny, violence and inhumane treatment of other humans. Butake uses animals in their real nature to make man reconcile with man.

\section{Methodology}

The method of analysis is a descriptive approach that describes the proverbs and the relationship between the animals used in the proverbs, showing opposition in the animal camp. The transitivity theory is used in analysing the proverbs relating the processes to the atmosphere created in the play by the playwright. The used processes are presented in percentages which is calculated with the following formular:

$\underline{\text { Ratio }} \times 100$

Sum of Ratio

\section{Theoretical Basis}

Transitivity is the representation in language of process, the participants there in, and the circumstantial features associated with them. In other words, all those features of the clause which contribute to the linguistic representation of the speaker's experience come under transitivity. It is the analysis of the clause in terms of who is doing what to whom.

\subsection{Participants}

The Participants are the entities involved in the process and are the subjects within a clause, realised through the use of nominal groups. The participant's constituent can further be divided into participant roles such as actor, agent, goal, carrier, and sayer, each of the participant's roles corresponding with one of the six processes. 


\subsection{Processes}

Processes are expressions of happenings and doings, and can be viewed as events and are the pivotal components of a clause. Grammatical processes are realised by the use of verbal groups, which can be single or multiple words that show how language is structured to enable experiential meanings. Here different transitivity structures are described to portray how they allow clauses to realise different experiential meanings in texts. The different processes are: material, mental, relational, verbal, behavioural and existential. The material process is the process of doing, portraying physical action in the real world. This process has as participants: actor, the one who does the action; goal, the one who is affected by the action; recipient, the one who receives something and beneficiary, the one for whom something is done. The mental process makes us understand that life is not only about the outside world but also about the internal world of feelings, perception and thoughts. This process is a process of sensing and has three elements which are; perception affection and cognition. In the mental processes, there are two participants, namely: senser who is the one who does the mental action and phenomenon, which is the thing that is perceived, thought and appreciated. Relational process is the process of being. In relational clauses there are two parts to the being, which are, something said to be something else. In other words, a relationship of being is set up between two separate entities. This means that in a relational clause in English, there are always two participants. There are three types of relational process in the clause, namely: intensive, which establishes a relationship between two entities; circumstantial that defines the entity in terms of location, time, and manner; and possessive that indicates that one entity owns another. Each of these comes in two modes, attributive and identifying. The Relational Processes therefore express possession, equivalence, attributes. The participants are carrier, an entity being described, and attribute, the description of the entity; possessor, the one owning or containing something; possession, the thing owned or contained; token; an entity being equated with another and value, the other description. The behavioural process deals with human physiological and psychological behaviour. The participant of the behaver. Hancock (2005, pp. 110) gives examples of verbs that are of the behavioural process like 'laughed, danced, cried and moaned.'

The verbal Process is a process of saying. The participants of the process are: sayer, the participant who speaks or communicates, and the receiver, the one to whom the verbalisation is addressed. The verbiage is the name for the verbalisation itself. The existential process represents something that exists or happens. These clauses typically have the verb 'to be', or some verb expressing existence, such as 'to exist' and 'to arise', followed by a nominal group functioning as existent.

\subsection{Circumstances}

Circumstances describe background information for processes within the clause, such as time, place and manner. They are realised by adverbial groupings, prepositional phrases and by occasional nominal groups acting as adverbs. The different circumstantial elements are location, extent, manner, accompaniment, cause, matter, role, angle and contingency.

Gwilliams \& Fontaine (2015) examine certain aspects of indeterminacy as a problem presented to the analyst in using transitivity theory of Systemic Functional Linguistic. They argue that this aspect of language poses challenges to the analyst regardless of the approach taken. Indeterminacy in process type identification arises as a problem of Systemic Functional Linguistic users, resulting in analytical ambiguity - an uncertainty as to which process is being realised. Any uncertainty in analysis is problematic since it leads to inconsistent interpretations from different analysis. As Hancock (2005,pp.110-111) rightly says especially in the behavioural process, sometimes the same verb will shift properties in context, making a verb like 'woke' seems material in one context and behavioural in another, and even material/behavioural verb pairs as with 'kill and die', 'collapse and faint.' But as Gwilliams \& Fontaine argue, analysts should allow for full consideration of both the syntactic and semantic realisation of the clause and Hancock concludes that, the context plays a role in interpretation. This study takes into consideration the role of the context in interpretation.

\section{Discussions and Analysis}

The discussion and analysis is done in two sections that show how opposed animals are to each other, the presence of one keeps the other away. The second analysis uses the transitive aspect of processes to show that the linguistic choices of verbs add mean to the message of power and protest in the play, And Palm Wine Will Flow.

\subsection{Opposition in Animal Proverbs in And Palm Wine Will Flow}

The extensive use of animal image in the proverbs in Bole Butake's And Palm Wine Will Flow is a show of wisdom with the intention of combatting injustice, greed and tyranny. This is seen in the description and interpretation of the proverbs below.

The cockroach does not call a fowl to a wrestling match.

In objection to the Fon's appointment of Kibanya into the level of titled men, Shey Ngong goes to the grove when all roads are leading to the palace. The Fon's messenger tells Shey Ngong that the Fon will not take it kindly if he does not attend but Shey retorts 'my obligation is to the gods of the land ... Not to the Fon.' This is an open protest to make the messenger of the Fon understand that he, Shey Ngong does not support bribery, corruption and injustice. Voice's response is 'the cockroach does not call a fowl to a wrestling match.' According to Voice, Shey Ngong is the cockroach and the Fon the fowl and Shey should not find faults with the Fon because the Fon is of a higher authority 
than him. This highlights the theme of tyranny by those in authority. They think they can do anything they want and go free.

It is a foolish rat that argues with a cat

The Fon's messenger in support of the Fon tells Shey Ngong that 'it is a foolish rat that argues with a cat' implying that Shey Ngong is the rat and the Fon is the cat. The rat should not argue with the cat because the cat will eat it, not the other way round. The cockroach and the rat are preys to the fowl and the cat respectively. Voice therefore refers to Shey Ngong as the cockroach and the rat while the Fon is the fowl and the cat. The messenger considers Shey Ngong the lower person who is to bow to the Fon just like the cat does to the rat, because the Fon can do anything to him. He is therefore warning Shey Ngong to desist from protesting against the Fon's actions.

The gorilla can do nothing to an iroko tree

When the Fon's messenger insults Shey Ngong to be the rat and the cockroach and the Fon to be the cat and the fowl, Shey replies him with a proverb also, 'the gorilla can do nothing to an iroko tree' (88). In the African setting, Fons are referred to by the use of strong and powerful animals like lions, leopards, elephants, gorillas. Shey Ngong gives the Fon his due but takes a stronger stand. The gorilla is strong no doubt but it cannot break or uproot the iroko tree. This implies Shey Ngong's assertion of his superiority over the Fon. The Fon in carrying out injustice, bribery and corruption cannot fight against the people. Since Shey Ngong is for the people he takes a stronger stand against the Fon and his associates. This highlights the struggle for power as against the rights of the people. The proverb is a protest against the power in place.

The cat, no matter how full his stomach is, will never spare the rat.

Shey Ngong in his fearlessness reprimands Voice for being a stooge and goes on to tell Nsangong that, 'The cat, no matter how full his stomach is, will never spare the rat' (90). Here the greed of the Fon is compared to the cat and rat relationship. The Fon is so greedy that he would not spare anyone who opposes him. In his greed he sells 'red feathers to those who do not deserve it, and is not respected by the masses since he tramples on his people.' This proverb supports the theme of tyranny in the study, because the Fon uses his greed to terrorise the people into succumbing to his whims.

\section{Go and give the monkey his banana or he will never give you peace}

According to Nsangong, Shey Ngong should 'go and give the monkey his banana or he will never give you peace' (90). Nsangong supports the downtrodden against the Fon but is afraid to stand up against the ills of the Fon. He is afraid of what the Fon will do to Shey Ngong so he hurries to the grove to tell Shey to give up his fight against the Fon. Nsangong wants his rights but does not want to fight for it. In the Cameroonian society there are many of such cases of people who do not support the ills of the regime in place but send motions of support just to give 'the monkey his banana' so they might not be considered as black legs. Butake uses animals to show the fight going on between humans. This is tyranny because the people must support the Fon even in his wrong doing, before they can have peace.

The pig who knows only the hunger of its own stomach

The Fon of Ewawa shows concern only for himself, his family and those who go to him with gifts. With this greedy nature Shey Ngong considers the Fon as, 'the pig who knows only the hunger of its own stomach' (91). According to Shey Ngong the Fon's greed has suppressed the council of elders and the elders are there to give approval and acclaim every decision taken by the Fon. He does this because of greed. This is why Shey Ngong refers to him as a pig, since the pig is a greedy animal.

\section{The louse and the jigger have no need for brains}

Where there is tyranny there are always some subjects who are watchdogs, stooges and bootlickers of the tyrant. In And Palm Wine Will Flow the Fon gives these people the red feather and the farmlands of those who do not support him. Shey Ngong condemns these stooges and bootlickers around the Fon as 'the louse and the jigger who have no need for brains' (93). The louse and the jigger are parasites, living on their host. They have no need for brains, since they just have to act as the Fon commands and the Fon will give them the farmlands of others. This shows cowardice on the part of those who will not work but play stooge to the Fon, to have wealth.

\section{Incantations}

Shey Ngong uses another set of proverb when he is making incantations to send Kibaranko (masquerade) in search of palm wine in the palace. The proverbs show the power Shey Ngong possesses in the spiritual realm. He chants

Kwo'o! Kwo'o! Kwo'o!

The lion announces his presence with roaring.

The dog does not eat because he is hungry!

The leopard prowls among the goats and they scatter into the dark night!

The lion spreads terror among the cattle and the sheep!

When the elephant flaps his ears and sounds his trumpet,

The forest is in disarray for he has gone berserk! (104)

These proverbs give an insight to the violent nature of Kibaranko. It shows the strength of those who are protesting against injustice. The use of these proverbs show the power Shey Ngong has and the proverbs reflect protest because Kibaranko goes to stabilise the distabilised society of Ewawa. Kibaranko is compared to the roaring lion, the elephant's 
trumpet sound, the prowling leopard in the midst of goats and the terror the lion causes amongst cattle and sheep. These animals behave this way when their environment is not conducive, and so they protest against the unfavourable situations.

To receive Kibaranko after his outing, Shey Ngong chants another set of proverbs as follows:

The eagle flies and flies, but always returns home!

The prowling lion comes back to his den for rest!

After devastating the forest the elephant goes down to the river for a drink!

The farmer spent all day in the fields, but returned home at dusk and went to sleep! (107)

These proverbs are to cool down Kibaranko and reassure the oppressed of calm after a struggle for what belongs to them. Kibaranko comes back not with the palm wine for temporary incantations but with the Fon's bugle, an indication of power changing hands. Kibaranko comes back after devastating the palace by setting it on fire. The burning of the palace signifies the destruction of the old order and the bugle comes with a new beginning.

Pride drove the goat to wrestle with the leopard

When the Fon's messenger complains to Shey Ngong of Kibaranko's destruction in the palace, Shey Ngong replies, 'Pride drove the goat to wrestle with the leopard' (106). Shey Ngong is the King maker and considers himself to be more powerful than the Fon but the Fon thinks highly of himself and wants to fight with Shey. Kibaranko's action has therefore proven who is more powerful. That is why the Fon who is the goat, should not wrestle with Shey Ngong, the leopard.

The rat does not play with the cat

Gwei comes in with a message from the Fon warning Shey Ngong to be careful about his actions against the Fon. He says 'The rat does not play with the cat' (101). This is because they consider the Fon to be greater than Shey Ngong. This goes again to highlight the tyranny of the Fon. He addresses himself as the cat because the cat is a tyrant in the presence of the rat. This potrays that the Fon does not want to see any one in Ewawa who does not support him.

The disease that attacked the cow cannot spare the goat

When Tapper is told to get palm wine from the palace he retorts, 'The disease that attacked the cow cannot spare the goat' (101). Tapper is an associate of Shey Ngong and just like Nsangong who is beaten, it is evident that if they lay hands on Tapper, the Fon's thugs will also beat him. Tapper is afraid of what is being done to those who do not support the Fon. The Fon's thugs beat people and make some to disappear.

Here are the fruits they urged me feed the crocodile that swallows its own eggs!

In delivering 'the wares the women commanded' to the Fon, Kwengong tells him, the Fon, 'Here are the fruits they urged me feed the crocodile that swallows its own eggs!' (110). The Fon is the crocodile that swallows its own eggs because he maltreats his own people. He is supposed to be a man of great power, ruling with justice and equality. This is the type of leader who does not fight for his people but rather fights for his own interest. The Fon of Ewawa is to be the elephant of Ewawa, but he is instead the one propagating bribery and corruption. Since he cannot stand in support of the masses, they send to him urine and call on him to drink it and die, so as to deliver the land from the abomination of drunkenness and gluttony, because as Kwengong tells him, 'The people need your death to think!' (110).

Through the proverbs, the masses complain of being maltreated by those in power. The use of proverbs in And Palmwine will Flow, show that Butake's intention is first to raise awareness, followed by the issue of identity and lastly by outright protest. In his proverbs Butake uses animals and in most cases to show life in the jungle, where the cat wants to eat the rat or the fowl wants to get whole of the cockroach. This is to show the fight over power, because everyone wants to be in authority. The proverbs highlight the themes of protest, greed and tyranny. Butake uses animal imagery to vividly express the combat going on in the human society and show how mean living in two camps, oppressor and oppressed, could be. This is shown through contrastive pairs, showing one entity to be more powerful than the other. The fowl is more powerful than the cockroach, the cat more powerful than the rat, the Iroko tree more than the gorilla, the monkey can eat the banana, the leopard is more powerful than the goats, the elephant can trample down ants, the crocodile eats eggs, the hare is more powerful than the tortoise, cows are more powerful than flies, the cattle and sheep are afraid of the lion, and all other animals are afraid of the elephant. The proverbs are mostly said by Shey Ngong, Nsangong, Tapper and Kwengong from the camp of the oppressed and a few are said by Voice from the camp of the oppressor.

\subsection{Process Patterns}

The Systemic Functional Grammar is a method of analysis that attempts to analyse texts to discover sub-codes or patterns of representation which construct or represent the world. Through Systemic Functional Grammar the study investigates how a data can help reveal the ideologies represented in the text. The study adopts the process patterns approach used by Goatly (2008,pp. 53-54). This approach reveals latent ideology through looking at patterns of verbs, using the transitivity analysis of Systemic Functional Grammar. The Ratio is 26:5:3:3. The percentages are found on Table 1. below. 


\begin{tabular}{|c|c|c|c|c|}
\hline $\mathrm{SN}$ & PROCESS & VERB & Frequency & $\%$ \\
\hline 1 & Material & $\begin{array}{l}\text { Do, Go, Give, Drove, Wrestle, } \\
\text { Attacked, Feed, Swallows, Trampled, } \\
\text { Eaten, Beating, Beat, Beaten, Knock, } \\
\text { Prowls, Scatter, Spreads, Flaps, Gone, } \\
\text { Flies, Returns, Comes, Goes, Give, } \\
\text { Devastating, and Wrestle }\end{array}$ & 26 & 70.3 \\
\hline 2 & Mental & Spare, Knows, Seen, See, Spare & 5 & 13.5 \\
\hline 3 & Verbal & Call, Argues, Announces & 3 & 8.1 \\
\hline 4 & Relational & Have, Has, Been & 3 & 8.1 \\
\hline \multicolumn{3}{|c|}{ TOTAL } & 37 & 100 \\
\hline
\end{tabular}

The overall presence of the material process shows action that goes with conflict and protest. Shey Ngong and his camp (kwengong, Tapper, Nsangong) are the ones using the proverbs. In the proverbs they place the opposition camp on the protesting side and the more powerful animals are on their side. They are the leopard against the goat, the lion against the cattle/sheep, the hare against the tortoise, the elephant against the ants, and the cow against the flies. On the oppressor's side they are considered as parasites, louse and jiggers with no brains, the crocodile that eats its own eggs, the rat, goat, tortoise, cattle/sheep, flies, cockroach that are powerless in the sight of their opponents. The oppressors have power only when greed is being manifested as in being the cat that considers only its own stomach over the rat and the fowl that eats the cockroach.

\title{
7. Conclusion
}

The results of the research reveal that the proverbs used by Butake has four processes: material, mental, relational and verbal at the ratio: 26:5:3:3 which gives percentages.In the Holy Bible, the Psalmist writes about the position of man against all other of God's creatures in Psalm 8: 6-8

\author{
Yet you made him inferior only to yourself \\ You crowned him with glory and honour \\ You appointed him ruler over everything you made; \\ You placed him over all creation \\ sheep and cattle, and the wild animals too; \\ the birds and the fish and the creatures in the seas.
}

According to the Christian faith therefore, man is above all creatures, and biologically, man is the most advanced of all animals. Butake, in agreement with the notion that man is higher, fights greed, injustice and power monger in man by using animal imagery in his proverbs to show the beastly nature of man. In addition man knows the lowliness of animals and will understand better the use of animal imagery for man not to be greedy and suppressive. Butake brings man to the level of the animal because he wants reconciliation in the human society. This is the reason for the excess use of the material process which shows action. Transitivity as used in this study correlates linguistic choices and social aspects of language use and brings out the underlying message of protest in the play. This portrays that the linguistic choices made by Butake in And Palm Wine Will Flow are as a result of sociocultural experiences and the effects they have on Butake's world view at the time of writing.

\section{References}

Ademowo, A.J. \& Balogun, N. (2014). Proverbs in Conflict Management in Africa: A Study of Selected Yoruba Proverbs and Proverbial Expressions. International Journal of Literature, Language and Linguistics, 1(1), pp. 039-044.

Adesina, L.O. (2015) “Pragmatic Use of some Proverbs on 'Egungun' Among Yoruba Speakers”. Journal of Humanities and Social Sciences, 20(12), pp. 1-6

Alimi, S.A (2012). A Study of the Use of Proverbs as a Literary Device in Achebe's Things Fall Apart and Arrow of God. International Journal of Academic Research in Business and Social Sciences, 2(3).

Asaki, I.E. (2012). Telling the African side of the story:Proverbs as a Crucial Element in Uchenna Nwosu's The Rejected Stone. UJAH: Unizik Journal of Arts and Humanities, 13(1), pp. 14-33. http://dx.doi.org/10.4314/ujah.v13:1.2

Ashipu, K.B.C \& Amende, C. (2013). Proverbs as circumstantial Speech acts. Research on Humanities and social sciences, 3(7), pp. 10-15

Butake, B. (1999). Lake God and Other Plays. Yaoundé: Editions Cle.

Cunanan, B T (2011). Using Transitivity as a Framework in a stylistic analysis of Virginia Woolf's Old Mrs. Grey. Asian EFL journal, 54, pp. 69-79. 
Deepak, K (2011). Literarism: The republic of letters. Literarism.blogspot.com/2011/04/animal-imagery-ted-Hughes, html.

Fomukong, S.E.A. (2016). A Cogni-Pragmatic View of Proverbs in Nkengasong's Across the Mongolo: An Eco-cultural Decoding of Codes. International Journal of Applied Linguistics \& English Literature, 5(1), pp 156-160. Doi:10.7575/aiac.ijalel.v.5n.Ip.154.

Gwilliams, L and Fontaine, L. (2015). Indeterminacy in process type classification. Functional Linguistics. Doi: 10.1186/s40554-015-0021_x

Haratyan, F. (2011). Halliday's SFL and Social Meaning. $2^{\text {nd }}$ International Conference on Humanities, Historical and

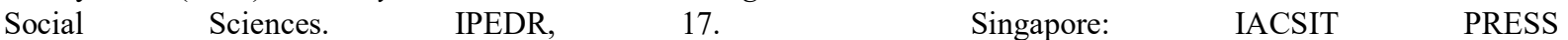
http:/functionalinguistics.springeropen.com/articles/10.1186/s40554-015-0021_X

Bustam, M.R. (2011). Analyzing Clause by Halliday’s Transitivity System. Journal llmu Sastra, 6(1), pp. 22-34

Jick, H., and Ngeh, A.T. (2002). The Moral Concept of Violence in African literature: Bole Butake's vision in 'Lake God' and 'And Palm Wine Will Flow.' Humanities Review Journal, 2(2).

Ngwang, E.N., \& Usongo, K. (2016). Art and Political Thought in Bole Butake. U.S: Lexington Books.

Obiechina, E. (1993). Narrative Proverbs in the African Novel. Research in African Literatures, 24(4), pp. 123-140. Indiana University Press.

Swallow, K. (2011). Ask the Animals, and they will Teach You. www.flourishonline.org/2011/07/lessons-fromliterature-about-animals/

Taken, T. (2002). Multiculturalism and the Politics of Nation. Building in Recent Cameroon Anglophone Theatre. Applied Theatre researcher, 6(3), pp. 1-18.

Wattles, I., \& Radic-Bojanic, B. (2007). The Analysis of An Online Debate-The Systemic Functional Grammar Approach. Linguistics and Literature, 5(1), pp.47-58.

Zheng, S., Yang, A., \& Ge, G. (2014). Functional Stylistic Analysis: Transitivity in English-Medium Medical Research Articles. International Journal of English Linguistic, 4(2). DOI: 10.5539/ijel.v4n2p12

\section{APPENDIX}

Proverbs in And Palm Wine Will Flow used for analysis

The cockroach does not call a fowl to a wrestling match

It is a foolish rat that argues with a cat

The gorilla can do nothing to an iroko tree

The cat no matter how full his stomach is will never spare a rat

Go and give the monkey his banana or he will never give you peace

The pig who knows only the hunger of its stomach

Pride drove the goat to wrestle with the leopard

The disease that attacked the cow cannot spare the goat

Here are the fruits they urged me feed the crocodile that swallows its own eggs

$\mathrm{He}$ is not the sun that strides majestically in the sky

We are not ants to be trampled down by an elephant

Now you lick oil dripping from the Fon's fingers as he eats chicken

The leopard does not wrestle with the goat

The louse and the jigger have no need for brains

The leopard and the goat have never eaten from the same dish

The leopard and the goat have never been bedfellows

Have you seen an owl beating its wings in broad day light

Did the tortoise really beat the hare in the racing match

No tortoise has beaten the hare

You are not a cow that can knock a horde of flies

Never try to fight another's battle for him

So that all the people shall see clearly that the fowl has an anus

The lion announces its presence with roaring 
The leopards prowls among goats and they scatter into the dark night

The lion spreads terror among the cattle and the sheep

When the elephant flaps his ears and sounds his trumpet, the forest is in disarray for he has gone berserk

A messenger does not receive the blows meant for the sender of the message

The eagle flies and flies, but always returns home!

The prowling lion comes back to his den for rest!

After devastating the forest the elephant goes down to river for a drink!

The farmer spent all day in the fields, but returned home at dusk and went to sleep!

The disease that will kill a man begins like an appetite 